\title{
Número especial: perspectivas de las ciencias vegetales
}

\section{INTRODUCCIÓN}

El análisis de la situación actual de las ciencias vegetales y sus perspectivas de desarrollo es el tema de este número especial el cual reune las contribuciones de 26 botánicos en 18 artículos.

A manera de introducción de este número y para presentar cada una de las contribuciones, revisamos brevemente tres reuniones científicas para comparar las tendencias actuales del desarrollo de la botánica desde una escala mundial hasta una local. Los eventos analizados son: (i) el XV Congreso Internacional de Botánica celebrado en Yokohama, Japón en el año de 1993, (ii) el VI Congreso Latinoamericano de Botánica celebrado en Mar del Plata, Argentina en 1994 y (iii) el Congreso Mexicano de Botánica celebrado en Yucatán, México en 1993.

Uno de los eventos más representativos.del quehacer científico en el área de las ciencias vegetales son los Congresos Internacionales de Botánica que se llevan a cabo cada seis años en diferentes países. En el último Congreso Internacional participaron más de 4000 personas provenientes de 54 países organizados alrededor de ocho grandes secciones. Estas fueron: (1) sistemática y evolución, (2) ecología y botánica ambiental, (3) estructura y su dinámica, (4) fitoquímica y productos naturales, (5) metabolismo y bioenergética, (6) crecimiento y desarrollo, (7) genética y (8) biotecnología. Se presentaron 3257 trabajos de los cuales el $67 \%$ fueron presentaciones en carteles y el resto en exposiciones orales.

Para fines comparativos utilizamos esta clasificación agregando además, las secciones de etnobotánica y paleobotánica para cubrir algunos trabajos presentados en los Congresos Latinoamericano y Mexicano de Botánica.

En el VI Congreso Latinoamericano se presentaron 664 trabajos en forma de cartel y en el último Congreso Mexicano se presentaron 775 trabajos. En el presente análisis no consideramos los simposios de estos congresos por el número relativamente bajo de exposiciones y el relativo sesgo de los temas tratados.

El análisis del número de trabajos presentados por sección o tema nos arroja resultados muy interesantes. Por un lado, es sorprendente la similitud en el número de trabajos en la mayoría de las secciones en el Congreso Internacional. Por ejemplo, las secciones de estructura y su dinámica, fitoquímica y productos naturales, genética y biotecnología oscilan alrededor del 11\% (356 a 386 trabajos). Con un mayor porcentaje se encuentran las secciones de sistemática y evolución (16.3\%), ecología y botánica ambiental (17.9\%) y crecimiento y desarrollo (15.6\%) (531, 584 y 507 trabajos respectivamente). La sección con un menor número de trabajos es el de metabolismo y bioenergética con 225 trabajos $(6.9 \%)$.

Como en la mayoría de las reuniones botánicas los trabajos sobre sistemática y ecología son los que predominan y esta tendencia también se presentó en el Congreso Latinoamericano y en el Mexicano de Botánica (Cuadro 1). En el Latinoamericano el número de trabajos sobre sistemática, florística, fitogeografía y temas afines fue de 311 (46.8\% del total). Es indudable que este tipo de estudios seguirán incrementándose dada la falta de estudios taxonómicos y florísticos en muchas regiones de América Latina.

Lo más sorprendente del Congreso Internacional es la magnitud de estudios en la sección denominada crecimiento y desarrollo. Esta sección cubre investigaciones sobre crecimiento y diferenciación celular, crecimiento y desarrollo de órganos vegetativos, desarrollo de órganos reproductivos, fotorregulación y desarrollo, substancias que influyen en el crecimiento y respuestas a factores de estres ambiental. Este tipo de investigaciones no encuentran igual representatividad en los congresos Latinoamericano y Mexicano. Es notoria la carencia de investigaciones sobre estas temáticas en México o al menos no se ven reflejadas en el Congreso Mexicano de Botánica (Fig. 1). Probablemente, los estudios sobre este tema en México sean presentados en los congresos de bioquímica, biología celular o biología molecular.

Comparativamente, también es interesante que cuatro de las secciones mencionadas presentan un número similar de trabajos. Nuevamente, investigaciones sobre temas de estas cuatro secciones son escasos en México. Es notoria la falta de trabajos en áreas como estructura (anatomía, morfología floral, organografía, estudios de organelos, pared celular, etc.), fitoquímica y productos naturales, 
CuAdro 1. Frecuencia relativa del número (\%) de trabajos presentados en el XV Congreso Internacional de Botánica (Yokohama, Japón, 1993), el VI Congreso Latinoamericano de Botánica (Mar del Plata, Argentina, 1994) y el XII Cogreso Mexicano de Botánica (Mérida, México)*.

\begin{tabular}{|c|c|c|c|c|c|c|}
\hline \multirow{2}{*}{$\begin{array}{l}\text { Secciones } \\
\text { Sistemática y evolución }\end{array}$} & \multicolumn{2}{|c|}{$\begin{array}{l}\text { XV Congreso } \\
\text { Internacional } \\
\text { de Botánica }\end{array}$} & \multicolumn{2}{|c|}{$\begin{array}{l}\text { VI Congreso } \\
\text { Latinoamericano } \\
\text { de Botánica }\end{array}$} & \multicolumn{2}{|c|}{$\begin{array}{l}\text { XIII Congreso } \\
\text { Mexicano de } \\
\text { Botánica }\end{array}$} \\
\hline & 531 & $(16.3)$ & 311 & $(46.8)$ & 229 & (29.6) \\
\hline Ecología y botánica ambiental & 584 & (17.9) & 106 & $(16.0)$ & 325 & $(41.9)$ \\
\hline Estructura y su dinámica & 356 & (10.9) & 103 & $(15.5)$ & 39 & $(5.0)$ \\
\hline Fitoquímica y productos naturales & 362 & $(11.1)$ & 36 & $(5.4)$ & 28 & (3.6) \\
\hline Metabolismo y energética & 225 & $(6.9)$ & 4 & $(0.6)$ & 7 & $(0.9)$ \\
\hline Crecimiento y desarrollo & 507 & $(15.6)$ & & - & & - \\
\hline Genética & 306 & $(9.4)$ & 25 & (3.8) & 12 & (1.6) \\
\hline Biotecnología & 386 & (11.9) & & - & 8 & $(1.0)$ \\
\hline Etnobotánica y áreas afines & & - & 45 & $(6.8)$ & 67 & (8.7) \\
\hline Paleobotánica & & - & 34 & $(5.1)$ & 60 & (7.7) \\
\hline Total & $325^{\prime}$ & & 664 & & 775 & \\
\hline
\end{tabular}

* Datos tomados de los resúmenes oficiales de los Congresos mencionados.

genética y biotecnología. Seguramente, los investigadores de algunas de estas áreas también tienen sus foros en congresos particulares sobre bioquímica, química, biología molecular y biotecnología. Sin embargo, los estudios sobre estructura en Latinoamérica están bien representados con el $15.5 \%$, casi igual que el porcentaje de trabajos de ecología (16\%).

Al comparar los tres congresos, el Internacional, el Latinoamericano y el Mexicano, resalta la carencia de estudios etnobotánicos, de botánica económica o temas afines en el congreso internacional. En el congreso latinoamericano y en el mexicano el número de contribuciones es alto lo cual refleja la riqueza cultural que albergan las comunidades humanas en el uso tradicional de los recursos vegetales. Sin embargo, hay que reconocer que existen los congresos propios sobre botánica económica o etnobotánica en donde participan investigadores de otros países, pero aun asi, siguen prevaleciendo este tipo de temas a nivel latinoamericano y sin lugar a dudas, en México.

\section{PERSPECTIVAS DE LAS CIENCIAS VEGETALES EN MÉXICO}

El desenvolvimiento de la investigación en las ciencias vegetales ha sufrido una serie de transformaciones muy importantes en años recientes. Fundamentalmente estos cambios giran alrededor de dos vertientes. Por un lado, todo lo concerniente a la conservación de la biodiversidad y el manejo de los recursos naturales, y por el otro, el desarrollo de la investigación en biología molecular y sus aplicaciones a problemas de taxonomía, ecología o genética.

El problema de la conservación de los recursos naturales ha sido motivo de preocupación en todo el mundo, y la investigación sobre esta temática se ha diversificado notoriamente. Por un lado, se han intensificado los estudios de campo para elaborar inventarios florísticos y faunísticos de regiones geográficas poco exploradas. Esta tarea se ha vuelto priotaria a nivel mundial y México no ha sido la excepción. Con esto se ha estimado el número de especies presentes en distintas regiones con diferentes grados de diversidad que han permitido delinear medidas tendientes a la conservación de ellas. Simultáneamente, se ha intentado completar los inventarios de grupos de organismos específicos que no han recibido la atención adecuada y que, preocupados por la acelerada destrucción de los ecosistemas naturales, ven amenazada la posibilidad de que se completen estos inventarios. Esta última tendencia se refleja en varios de los trabajos de este número especial. Por ejemplo, los inventarios micológicos (G. Guzmán) y florísticos en general (P. Dávila y V. Sosa).

Además, existe la idea de que el análisis de la riqueza biológica nacional tiene repercusiones muy importantes en las investigaciones sobre cuestiones ecológicas (M. Martínez-Ramos) o sobre el descubrimiento de compuestos químicos de importancia económica (A. Anaya-Lang; E. MorenoMartínez). 
Paralelamente, R. Dirzo y P.H. Raven hacen una propuesta que denominan el Inventario Biológico Nacional. En esta propuesta enfatizan la importancia de incluir los inventarios biológicos en bancos de datos computarizados, la coordinación de las organizaciones e instituciones albergadoras de colecciones científicas, la formación de recursos humanos y la creación de bancos de propágulos, entre otras cosas. Algunas de las sugerencias de estos autores, ya están siendo desarrolladas por varias instituciones y organizaciones en el país. Al parecer, el problema radica, por un lado, en coordinar las diferentes fases de investigación que realizan diversas instituciones sobre cuestiones de biodiversidad, y por el otro, en organizar, sistematiza: y financiar aspectos que no han sido desarrollados adecuadamente como por ejemplo, los bancos de propágulos que requieren de una gran inversión no sólo económica sino humana.

En este contexto, es muy importante considerar análisis particulares para poder evaluar adecuadamente la situación de los inventarios biológicos. Un ejemplo de este tipo de análisis es el que realizan P. Dávila y V. Sosa sobre los estudios florísticos realizados en México. Se analiza el estado actual de los estudios florísticos regionales en donde 16 proyectos de esta naturaleza cubren aproximadamente $70 \%$ del territorio nacional, lo cual refleja un avance sustancial. Otro aspecto de esta misma problemática lo ilustra el trabajo de G. Guzmán sobre las malas condiciones en las que se encuentran algunas de las colecciones de hongos existentes en instituciones mexicanas. Se pueden proponer varias ideas de inventarios biológicos pero simultáneamente, deben de resolverse cuestiones básicas como el resguardo adecuado de las colecciones científicas.

Otra línea de investigación sobre el manejo de los recursos naturales se concentra en los estudios sobre el uso tradicional en diferentes comunidades humanas. Este enfoque etnobotánico etnoecológico ha logrado dilucidar el valor del conocimiento tradicional en el uso de los recursos naturales. En la actualidad, los estudios etnobotánicos integran conocimientos generados por especialistas en sociología, economía, antropología, etc. y han incorporado modelos y métodos cuantitativos lo que ha permitido estudiar este tipo de problemática de manera holística y formal. $\mathrm{Al}$ respecto, en este número se presenta un análisis muy detallado del quehacer etnobotánico en ramas como medicina tradicional, plantas comestibles, domesticación de plantas silvestres, origen de la agricultura, etc. (M. Martínez-Alfaro). Este interesante análisis revela la gran riqueza cultural y la trascedencia de este tipo de estudios en América Latina.

Existen otros enfoques sobre el manejo de recursos naturales y sobre todo, grupos de investigación dedicados al análisis de regiones particulares de nuestro país que incluyen, además de los puntos mencionados, cuestiones como sustentabilidad que requieren de una revisión particular. Esperamos contar con una revisión de este tema por parte de los especialistas mexicanos en el futuro.

La otra vertiente de investigación a nivel mundial se encauza con el desarrollo de la biología molecular y su aplicación en las diferentes áreas del concocimiento. M. Lara-Sánchez y F. SánchezRodríguez nos plantean algunos métodos desarrollados en la biología molecular para la transformación de plantas y sus aplicaciones en problemas como resistencia de malezas a herbicidas, resistencia de plantas a bacterias, virus e insectos, etc. Este tipo de aplicaciones se extienden cada vez más a áreas como ecofisiología vegetal (C. Vázquez-Yanes), ecología (M. Martínez-Ramos), micología (T. Herrera) y fitopatología (E. Moreno-Martínez). Además, es indudable el surgimiento de nuevas áreas en la botánica como la sistemática molecular y la ecología molecular. El vigoroso crecimiento de la investigación en estas nuevas ramas botánicas requerirá de una revisión de nuevos conceptos, métodos y sobre todo de los resultados que generen estas investigaciones en un futuro no muy lejano. De hecho, estas temáticas ya se empiezan a reflejar en la producción científica nacional.

Asimismo, el análisis del desarrollo de la investigación en diferentes áreas como la paleobotánica (R. Weber y S. Cevallos-Ferriz) o grupos de plantas como algas (M. Ortega y J.L. Godínez), pteridofitas (R. Riba y B. Pérez-García) y más particularmente, en grupos como las palmas (H. Quero), indican que este desarrollo se encuentra en un buen momento integrándose al conocimiento universal. Es obvia la necesidad de análisis similares para otros grupos de plantas (por ejemplo, musgos), o de grupos particulares de familias de plantas (por ejemplo, Leguminosae, Graminae, Asteraceae, Rubiaceae, Solanaceae, etc.) o de comunidades vegetales particulares (por ejemplo, bosques caducifolios, bosques mesófilos, etc.). Además, áreas tan importantes como la fitogeografía requieren de científicos nacionales dedicados a realizar estudios y análisis de la situación actual y desde luego, sus perspectivas. La comunidad botánica está en espera de estos análisis y reflexiones.

La formación de recursos humanos para el desarrollo adecuado de las ciencias vegetales en México es fundamental. P. Moreno-Casasola realiza un análisis sobre los niveles de formación en ciencias vegetales en las diferentes instituciones educativas y de investigación del país. Este análisis 
utiliza como contexto la problemática de la biodiversidad y de las necesidades de investigación no sólo en la elaboración de inventarios biológicos sino también en el conocimiento de su genética, fisiología, ecología y sistemática.

Los programas de formación de recursos humanos en ciencias vegetales, incluyendo las cuestiones agronómicas y ambientales, se han incrementado notoriamente en el país (P. Moreno-Casasola). Estos programas, si bien están concentrados en el centro del país, empiezan a generarse en otras regiones. Esto puede ser un reflejo de la creación de centros de investigación regionales los cuales han tenido un impacto considerable en la creación de programas educativos y por ende, de la formación de personas capacitadas en diferentes áreas. Sin embargo, este exhaustivo análisis aún muestra la carencia de personal especializado sobre todo a nivel de doctorado.

En este mismo sentido, F. Chiang, P. Dávila y J.L. Villaseñor mencionan la fuerte carencia de personal capacitado para realizar investigación en taxonomía y sistemática y plantean, entre cosas, la creación de un posgrado en estas áreas.

El papel que ha jugado el Boletín de la Sociedad Botánica de México ha sido fundamental como órgano de difusión científica de la comunidad botánica nacional. A. Lot y A. Butanda realizan un análisis y muestran que el BSBM ha publicado trabajos notables no sólo a nivel nacional sino también con repercusión a nivel internacional. En este análisis, también se destacan puntos sobre las publicaciones en el BSBM en el contexto de los sistemas de evaluación de los investigadores.

El impacto que pueda tener el BSBM recae tanto en la calidad de los artículos como en la profesionalización de la edición y distribución de la revista. Este señalamiento no es nuevo, pero lo importante es como superarlo. En cuanto al contenido, está en manos de los botánicos; en cuanto a la edición y distribución, está en manos de los miembros de la Sociedad Botánica de México tomar las medidas pertinentes. 